\title{
Industrias, arquitectura vernácula, territorio y patrimonio cultural en Constantina
}

\author{
Gema Carrera Díaz \\ Grupo de Investigación GEISA \\ Departamento de Antropología \\ Universidad de Sevilla
}

\section{Resumen}

Aunque parezca un difícil juego de malabarismo conceptual, el título que encabeza este artículo tiene sentido. A través de la arquitectura, concentrada y dispersa en el término municipal de Constantina, sobre todo la relacionada con actividades industriales o protoindustriales (producción de vino, aguardientes, corchos, curtidos, embutidos...) en las que se transforman o transformaban los productos propios de la explotaciones agropecuarias locales, podemos hacer varios análisis relacionados con la economía, el territorio y el patrimonio cultural de esta comarca de la Sierra Norte, de manera especial en Constantina, porque todos estos elementos se hallan íntimamente relacionados.

\section{Palabras Clave}

Territorio / Paisajes Culturales / Arquitectura vernácula / Patrimonio cultural / Actividades industriales / Élites locales / Cartografía etnográfica / Sistema de Información Geográfica

Desde posiciones del determinismo geográfico, muy extendidas entre muchos técnicos y científicos sociales y que han calado eficazmente en la conciencia general de la población, se tiende a identificar las zonas serranas como esencialmente poco productivas, intrínsecamente pobres y, por tanto, con mayores dificultades para servir como soporte de un desarrollo económico sostenido, máxime si son comparadas con otras zonas de mayor "rentabilidad" como son los casos de las campiñas y vegas andaluzas. También, desde otras visiones culturalistas, se le ha adjudicado al empresariado andaluz, en este caso agroganadero, una mentalidad rentista y una falta de espíritu emprendedor, erigiéndose de este modo, en una de las piezas clave que explica la situación de estancamiento y subdesarrollo de buena parte de la Andalucía rural.

Sin embargo, tras un largo período de análisis y trabajo de campo realizado en la comarca de la Sierra Norte, y muy especialmente en Constantina, se puede concluir que la situación de estancamiento económico con que se define actualmente la comarca no ha sido una constante histórica, y no se explica por los factores deterministas a los que algunos aluden. Una lectura del rico patrimonio inmueble que aún perdura tanto en los núcleos principales de población, así como diseminado por los distintos términos municipales, nos enseña que desde siglos atrás hasta hace pocas décadas, la Sierra Norte se caracterizaba por tener una economía diversificada y articulada que pone en entredicho la carencia de recursos que, desde una perspectiva descontextulizadora, se les achaca a los espacios serranos.

Algunos de los factores históricos que explican la importancia de Constantina, dentro de la Sierra Norte y fuera de la misma, como un centro productivo importante durante el siglo XIX hasta mitad del siglo XX son su carácter de cabeza de comarca, ya que las poblaciones de Sierra Morena han tenido una fuerte vinculación con los grandes núcleos urbanos andaluces (Sevilla, Córdoba...), actuando como centros político administrativos del territorio andaluz, y es de suponer que siendo capital de comarca, esta vinculación sería aún más estrecha, con todos los beneficios que ello implica; en segundo lugar, la estructura social de Constantina se caracterizó por la existencia de una poderosa burguesía agroganadera, de modo que en el siglo XIX y principios del XX el $50 \%$ de las fuentes económicas lo poseían el I I\% de la población. Esta burguesía agraria (que había hecho su fortuna a partir de las desamortizaciones ', fundamentó su poder político, económico y social, a nivel local y comarcal, en el latifundismo (sistema de explotación agrícola dominante en Andalucía); pero fueron también en buena medida los artífices del relativo desarrollo económico de la Sierra Norte de Sevilla durante el periodo señalado, potenciando un cierto proceso de diversificación económica y protoindustrialización basada en transformaciones de productos agropecuarios 2 (Carrera, G., 1999).

A partir de la aparición de una compleja maquinaria, la profusión de arquitectura destinada a contener lagares, almazaras, fábricas de aguardiente, junto con grandes mansiones, haciendas y caseríos, reflejos del prestigio y posición social alcanzado por sus dueños, se puede deducir la importancia que tuvo esta burguesía en el desarrollo económico de la comarca, siendo los artífices de una importante red de actividades de transformación en el hábitat disperso de Constantina, y en su casco urbano.

En este sentido, creo que es interesante hacernos preguntas acerca de las causas políticas y sociales, 
que hacen que un territorio rico en recursos como esta sierra se convierta en un momento dado en una zona, no pobre, sino marginal. Para ello creo que es interesante descifrar el hilo evolutivo de los cambios sufridos en las bases económicas: la previa existencia y posterior desaparición de diversas actividades productivas como el cultivo de la viña y la elaboración de vino, la fabricación de aguardientes, aceite; extracción y transformación de corcho, elaboración de curtidos, producción de embutidos etc. En definitiva el paso de la articulación a la desarticulación de la economía serrana. Es decir, en la Sierra Norte existió hasta la mitad del siglo XX un tejido productivo muy ligado a la explotación de los recursos locales que articulaba una serie de actividades económicas capaces de vincular toda la cadena productiva, desde la extracción de la materia prima a su transformación y posterior comercialización, que ocupaba a una buena parte de la población activa. Un sistema productivo que se fundamentó en una estructura social fuertemente polarizada, siendo muy pocos los que concentraron la mayor parte de los recursos económicos y el control de las instituciones político-administrativas para que este estado de cosas funcionara. La desaparición de este tejido económico, político y sociocultural (prácticas, conocimientos, relaciones sociales de producción. etc.), me llevan a considerar importante su análisis y su localización en el tiempo y en el espacio, como manera más efectiva de reconocer que realmente ha existido un cambio, o muchos cambios, y que estos han dejado su huella, no sólo en la memoria colectiva sino también en el territorio.

Y llegados a este punto, me gustaría contestarme a una pregunta fundamental ¿Cómo puede ser útil el estudio de estas actividades económicas, algunas desaparecidas, cuya existencia podemos deducir a partir de estas "arquitecturas" abandonadas, para la comprensión del territorio donde se encuentran, la Sierra Norte de Sevilla y el "Parque Natural"? ¿qué relación tiene todo ello con el patrimonio cultural del mismo? ies este territorio un patrimonio cultural en si?

Desde mi punto de vista, estos cambios y la impronta que estos han dejado en el territorio, constituyen, sin duda, un patrimonio cultural producto de la interacción entre medio y cultura, ya que actividad económica, territorio y patrimonio cultural están en algunos casos muy relacionados. Sobre todo, a partir de la actividad industrial o protoindustrial que se da en la Sierra Norte, muy ligada al territorio, pues se caracteriza por transformar los propios productos agropecuarios, siempre en consonancia con el medio.

En este sentido, en Constantina podemos ver la relación que existe entre recursos naturales y el hombre, cuyo resultado espacial es el espacio socializado o territorio, a través de varios ejemplos, como el aprovechamiento de los recursos hídricos, la toponimia, o la propia industria.

En cuanto al aprovechamiento de los recursos hídricos, basta citar la industria molinera y de curtidos, que hasta hace poco existió en la zona, y que se basó en el aprovechamiento de la fuerza que produce el agua del río de la Villa a su paso por el casco urbano. Cuando el arroyo está a punto de salir de la población se produce una concentración importante de instalaciones fabriles que aprovechan para su funcionamiento el caudal de aguas. Para ello, las aguas fueron canalizadas para potenciar y multiplicar su fuerza a través de conductos (caos) que las hacen acelerarse en el momento adecuado. Asimismo, el agua de la sierra ha quedado en el imaginario colectivo como uno de los recursos fundamentales que posibilitaron la riqueza de la industria del aguardiente en la zona. De este modo, el considerable número de arroyos que nacen en el término y lo atraviesan dio lugar a una importante infraestructura hidráulica, técnicas de aprovechamiento y arquitectura específica para el uso, distribución y economía de estos recursos: sistemas de canalización, riegos, fuentes, abrevaderos, pozos, etc. Desde el punto de vista espacial, el agua ha sido crucial en la configuración de la trama urbana. El propio asentamiento de la ciudad, que desde las faldas del castillo se ha ido extendiendo hacia el Este (Cerro de Luna), dejando así al río en el centro de la población, responde en parte a la necesidad de control de los acuíferos. Asimismo, la adaptación y apropiación de estos recursos hídricos por el colectivo ha dotado al paisaje de unas características y elementos singulares para sus habitantes como parte de sus referentes identificatorios. Fuera del entorno urbano, se mantendría la importancia del uso social y económico que se hace y se hizo de las aguas de los arroyos como "Aguaderos Reales" 3 cuando las vías pecuarias estaban en uso para la trashumancia y el comercio del ganado.

Por su parte, los topónimos (o nombres propios de lugar) son referentes espaciales, que en el ámbito municipal nos dicen mucho sobre el uso que se hace o ha hecho del territorio, y de la relación entre un determinado grupo social y un territorio dado. El topónimo es una abstracción que estamos habituados a usar para denominar a ciudades, pueblos, ríos etc. de dimensiones mayores, pero dentro de un término municipal, para el que no conozca bien el terreno, es difícil saber qué paraje, qué cerro o arroyo corresponde a un topónimo concreto. Para el forastero, en definitiva, los lugares pierden sus nombres, el paisaje se homogeneiza, perdiendo particularidades y matices, los arroyos son cursos de agua, pero no son arroyos particulares (La víbora, el Huérfano, la Viñuela..) y los cerros son elevaciones del terreno más o menos abruptas, pero no son tal o cual elevación del terreno (cerro de Luna, Cerro Colorado, el Negrillo...). Existen palabras para denominar lugares de dimensiones relativamente pequeñas, y el nombre existirá mientras ese lugar sea importante para los que lo nombran. De hecho, hoy día, las nuevas generaciones que no han trabajado el campo conocen muchos menos topónimos que los que vivieron y trabajaron en él, estos últimos hablan de los parajes y fincas como si de calles y barrios de un pueblo o ciudad se tratase. La toponimia es algo vivo pero es también un vestigio que nos habla de muchos aspec- 
tos desaparecidos de un determinado territorio. Para conocer el significado de un topónimo no basta con saber su etimología, es necesario "conocer el terreno por él denominado, los usuarios que lo perpetúan y alimentan cotidianamente. Y como no, todos aquellos que un día lo hicieron, algo que no nos dará sino la historia" (Gordón Peral, 1988).

Por ello, las bases económicas (agricultura, ganadería, minería...) son algunos de los aspectos fundamentales de los que nos habla la toponimia de la Sierra Norte. Y a partir de estas denominaciones de los lugares podemos deducir que existe una idea de espacio diferente expresada y comunicada colectivamente por los que habitan este territorio y que hace referencia a unos elementos comunes que los diferencia de otras zonas de la provincia como la campiña, el Aljarafe, la Ribera, y que podría justificar la existencia de una idea de la sierra como comarca, no sólo por los aspectos físicos del territorio serrano, sino también por los distintos procesos productivos que en ella se han desarrollado. En este mapa podemos apreciar las diferencias toponímicas existentes en Constantina, y sus relación en algunos casos con determinadas actividades productivas desarrolladas en la zona.

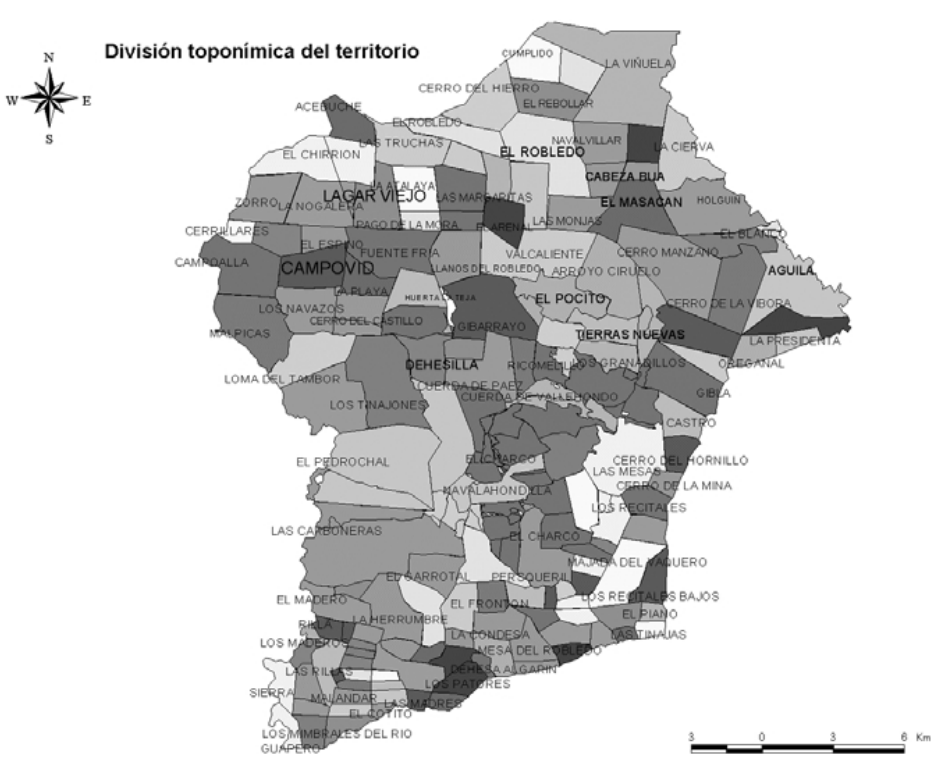

Todo este territorio, intensamente humanizado, forma hoy parte del "Parque Natural" de la Sierra Norte de Sevilla. La ley de Espacios Naturales Protegidos(1989), entiende por espacios naturales a proteger las zonas que "no han sido esencialmente modificadas por la acción del hombre, o bien lo han sido de tal modo que han generado nuevos ambientes naturales". ¿Cómo puede denominarse entonces "Parque Natural" a la Sierra Norte?, ¿cómo, sino eludiendo el continuo de transformaciones que las poblaciones que lo habitan han ido produciendo en él, formando todo ello parte de su propia cultura?. Como vemos el espíritu conservacionista de la ley es estrictamente naturista y desafortunadamente las repercusiones de su aplicación lo serán también. (J. Agudo, 2000). Términos como "espacios naturales", "patrimonio natural" pretenden hacernos pensar en lugares inalterados a través del tiempo. Sin embargo, el hombre actúa como cualquier otra especie dentro del ecosistema del que forma parte, adaptándose a él, pero lo que le diferencia de otras especie, es su capacidad de actuación transformadora. La necesidad de tener en cuenta este proceso de interacción cultura-medio no es nueva. La Unesco en 1992 (Boukhari. S, 1996) establece la categoría de "paisajes culturales" y los define como: "lugares que han sido creados, formados y preservados por los vínculos y las interacciones entre el hombre y su entorno"... "el éxito de su conservación depende del mantenimiento de esos vínculos".

Así mismo la Ley Andaluza del patrimonio Histórico ( I/199|), con su definición de "lugar de interés etnológico" ", enfatiza la huella que la cultura ha dejado en el paisaje. Ambas normas, una a nivel internacional y la otra a nivel autonómico, vienen a reconocer como parte de nuestro patrimonio los resultados positivos de la relación simbiótica hombre-medio, es decir, el "espacio social" o "territorio", una idea que entiende ese espacio considerado "natural" como sometido a reglas sociales; un espacio que pasa de ser un soporte físico a un factor cultural; una naturaleza que se percibe y se instrumentaliza, y que es reflejo de cada momento histórico, dependiendo de los diferentes modos de producción que cada sociedad ha ido articulando. De este modo, la transformación de la naturaleza hay que leerla no sólo en sus aspectos más perceptibles o materiales, es decir, no sólo cuando sirven como base para la reproducción biológica de un grupo, sino también sociocultural.

Por el contrario, proyectar esta imagen de un entorno inalterado significa olvidar o ignorar parte de lo que han sido los sistemas de aprovechamiento tradicionales de esta zona, y no en un pasado muy remoto, sino que se trata de sistemas que han coexistido durante este siglo. Parte de las dehesas que actualmente se venden como el único sistema de explotación autóctona de la zona, han sido hasta hace muy poco tierras de olivar, y anteriormente viñedos de producción muy apreciada, tanto por el vino como por los anisados elaborados con el alcohol vínico, y esta sucesión viña-olivar-dehesa, puede ser fácilmente interpretada en el término municipal de Constantina, así como en el de Cazalla. Las viejas edificaciones que albergaron lagares primero, y después almazaras, así nos lo demuestra.

Proyectar esa imagen, insistimos, supone olvidar que un edificio, un sistema de cultivo, un tipo de ganadería, un bosque, o un "monumento" no existen como realidades inmanentes, sino en relación con unos contextos históricos concretos que los han hecho posible y les otorgan su sentido. No comprender este vínculo, no contemplarlo y no aplicarlo, es poner en peligro la propia existencia de estos así llamados "parques naturales". 
Por el contrario, tener en cuenta todo el cúmulo de experiencias y prácticas que se han desarrollado en el seno de estos territorios hoy considerados parques, es darle su significación adecuada: sistemas de cultivos, prácticas ganaderas, actividades de transformación agroindustrial, aprovechamientos mineros, usos forestales, han contribuido a crear unos paisajes culturales que deben ser valorados como una parte más de las señas de identidad de la cultura andaluza.

Dentro de este contexto, es fundamental la actividad industrial o protoindustrial desarrollada en Constantina. $Y$ es que sin lugar a dudas, "La actividad industrial es un ejemplo paradigmático de cambio tecnológico, espacial, económico y social" (Giménez Yanguas, 1995-97). A partir de estas actividades se producen transformaciones y ampliaciones arquitectónicas, cambios tecnológicos que se van sucediendo a medida que cambian los procesos productivos, cambian los trabajadores implicados en los mismos, y los lugares en los que estas actividades se desarrollan. En virtud de este dinamismo se genera un patrimonio cultural relacionado con las actividades industriales o protoindustriales, materiales muebles e inmuebles y un conjunto de saberes y relaciones sociales que resultan útiles para reconstruir la historia de muchas regiones.

En este sentido, ésta sería en parte una reflexión sobre el patrimonio protoindustrial de una parte de la sierra sevillana. Por ello intentaré narrar algunas de las actividades de extracción y transformación que se iniciaron, desarrollaron y que terminaron por desaparecer en Constantina, ya que constituyen parte de las iniciativas empresariales locales, de ese mundo de pequeñas y medianas empresas, una industrialización silenciosa y olvidada pero que marcó a su gentes, en todos los aspectos, territorial, económico, social y cultural.
El cultivo de la viña y la producción de vino; la fabricación de anisados y licores; el cultivo del olivar y la producción de aceite; la dehesa, como sistema de aprovechamiento complejo y dinámico que genera gran cantidad de productos agropecuarios y de actividades de transformación de los mismos, tan variadas como: la producción de corcho, fabricación de tapones, cría del cerdo y producción de embutidos y chacinas, fabricación de curtidos, etc..., son las actividades productivas que más han caracterizado a esta zona, y que han marcado a su territorio y a su población, no sólo a nivel socioeconómico sino también cultural y simbólico.

Dentro de la Sierra Norte, el viñedo, aunque hoy sea un cultivo marginal, ha tenido un papel protagonista en la configuración del territorio de Constantina y Cazalla de la Sierra (Fernández de Paz, E., Montes de Oca, JM, Moreno, A: | 981 ), formando desde época romana parte de su paisaje. En el siglo XVI6 la producción vitivinícola vive su momento de mayor auge en la sierra.

Las tareas y labores vinculadas a la viña involucraban a un gran número de trabajadores durante todo el año; y los medios tecnológicos empleados en el prensado de la uva y su transformación en mosto (los lagares, en sus diferentes tipologías) condicionaron la arquitectura de muchos caseríos.

Pero el cultivo de la vid entra en una profunda crisis a fines del XIX, cuando tras diversas epidemias, llega la más letal de todas: la filoxera, que viene de Francia y que esquilma gran parte de los viñedos de la Península, disminuyendo la producción vinícola en un $50 \%$, afectando en mayor medida a los pequeños propietarios.

\section{ACTIVIDAD INDUSTRIAL}

A partir de la transformación de productos agropecuarios: producción de vino, aguardiente, aceite, embutidos, corcho.

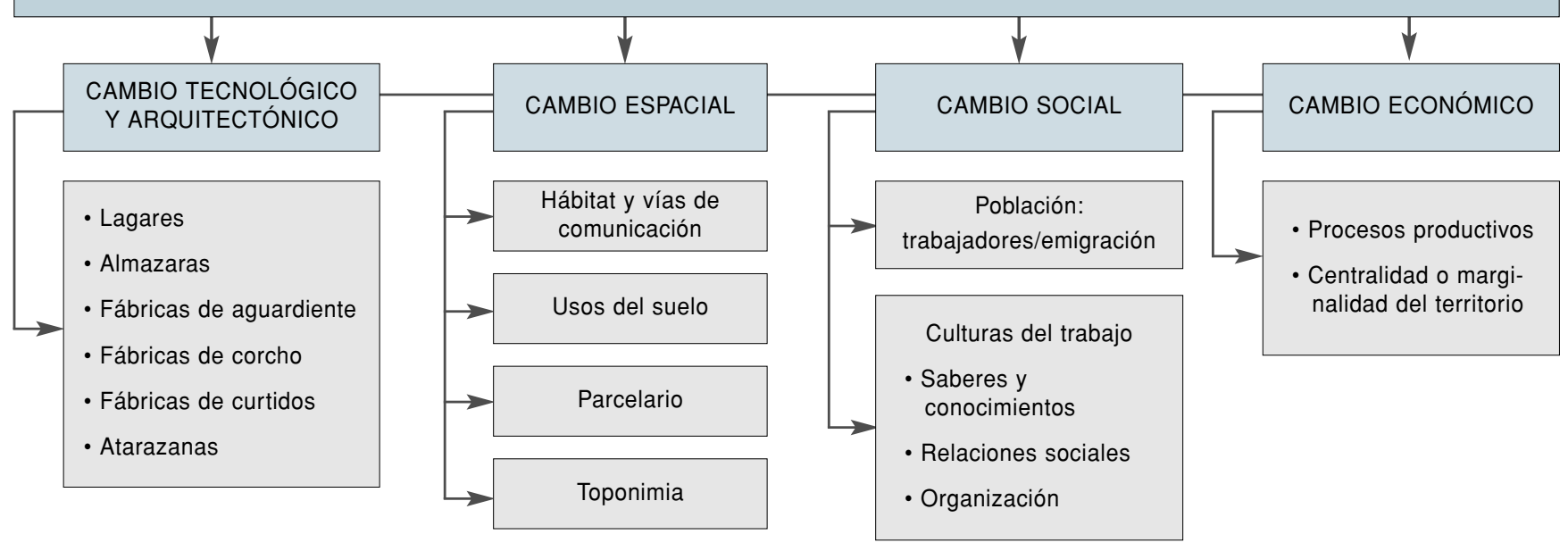


No obstante, a pesar de las adversidades, entrado el siglo XX, se implantan en la Sierra de Sevilla otras viñas, debido a la necesidad de mantener el cultivo que ocupaba a un mayor número de trabajadores al año (más que todo el resto de cultivos juntos), y a la resistencia a un cambio que, al final, vendría irremediablemente.

En los años cincuenta, los nuevos cambios a la baja en el mercado no serían soportados por los productores, y el olivar acaba por extenderse por los terrenos de viña, para acabar sustituyéndolo, siendo empleados los numerosos lagares que se localizaban por toda la geografía serrana, como almazaras. Desaparece así, en esta década un cultivo tradicional y social, dada la gran cantidad de mano de obra que ocupaba y que a su vez ocuparía el primer eslabón para la producción de vinos y aguardientes. El pequeño propietario, antaño viñista, se reconvierte en olivarero.

A partir de los mapas podemos observar la evolución de la desaparición del viñedo y de los edificios e ingenios para elaborar el vino (lagares). En el mapa de 1999 los lagares no representan nada si los comparamos con los que había en 1918, o los 750 que había contado Pascual Madoz.

Entre los lagares de Constantina hay una tipología que destaca por darse exclusivamente en esta zona, de forma tan repetida: el lagar de prensa de viga 8 de pequeñas dimensiones. En el cuadro podemos ver una clasificación de las diferentes tipologías de lagares:

La introducción de los lagares de prensa de husillo supuso un avance tecnológico importante, pues ocupaba mucho menos espacio que la prensa de viga, su mecanismo es mucho más sencillo y ejerce mayor presión (innovación comprensible si la situamos en las primeras décadas del siglo XX, momento en el que el viñedo disfruta de una leve recuperación debido a la coyuntura alcista del mercado durante la I Guerra Mundial) (Bernabé, 1998). La cercanía al municipio de estos nuevos lagares frente a la mayor distancia y dispersión de los anteriores, es reflejo del abandono que se está produciendo de las "industrias" diseminadas por el hábitat disperso, y de las transformaciones que esta nueva concentración urbana está provocando en el campo.

Como ejemplo paradigmático del desarrollo de la producción vitivinícola en Constantina, podemos destacar el caso de Las Bodegas de Fuente Reina que, en 1930, funda Manuel López Redondo, tomando el nombre del pago donde se encontraba su viñedo.

Fuente Reina se convierte en una bodega de renombre, apreciándose sus caldos y crianzas fuera de la comarca, fundamentalmente en Jerez de la Frontera. La bodega de Fuente Reina, de unas proporciones hasta el momento desconocidas en Constan-

\section{El cultivo de la viña en Constantina (I)}

Cultivos, 1918

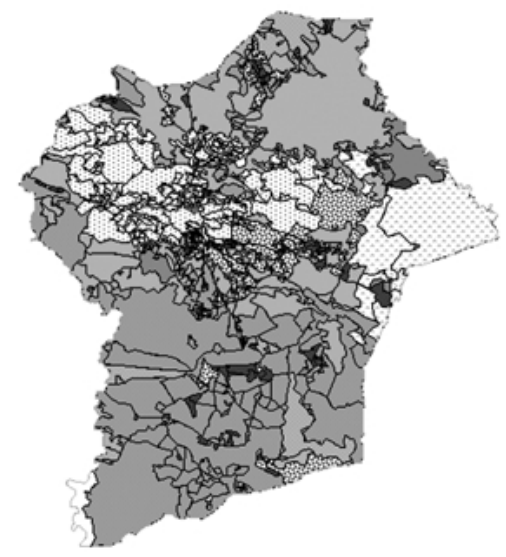

Area de Viñedo: 1900-1929

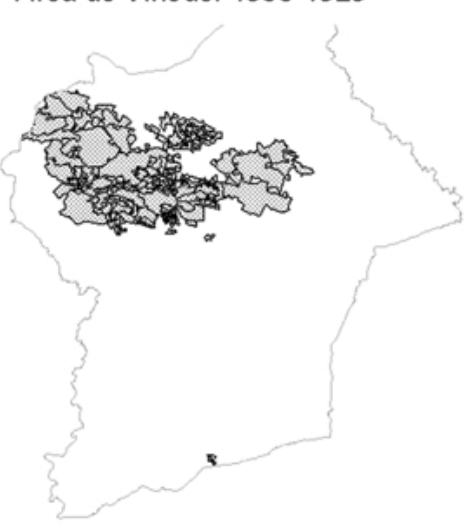

Cultivos, 1990

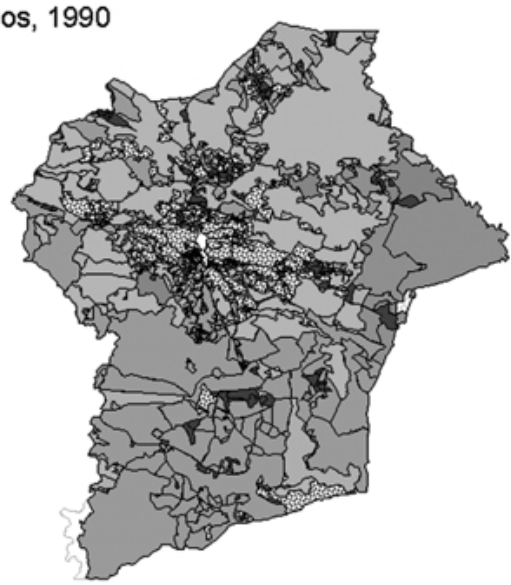

ERIAL

FRUTALES

HUERTA

MONTE ALTO

MONTE BAJO

MONTE BAJO/MONTE ALTO

OLIVAR

PRADOS Y DEHESAS

REPOBLACION FORESTAL

SECANO

VIÑEDO

Limites 
tina, está asentada dentro del núcleo urbano, respondiendo a la dinámica general de los años 50 , de concentración de industrias y viviendas dentro del pueblo y consecuente despoblamiento del hábitat diseminado.

Esta bodega supuso para Constantina romper con la tradicional limitación de producir caldos para ser vendidos fuera de la comarca o para la producción de alcohol vínico destinado a la elaboración de aguardiente, o de mosto para el consumo local, dando un paso adelante en la crianza y cosecha de vinos además de la elaboración de otro tipo de bebidas (aguardiente, brandy, ginebra..). Este bodeguero se interesó además por producir y criar vino tinto, que etiquetó además, como si de una denominación de origen se tratase, como VINO TINTO ANDALUZ.

Fuente Reina es también un ejemplo claro de uno de los últimos intentos de crear una industria local basada en los sistemas de cultivo y procesos de producción tradicionales, controlando todo el proceso desde el cultivo de la vid, la diversidad de productos resultantes de la elaboración del mosto y su posterior comercialización (el cultivo del viñedo se realizaba en la finca del pago de "Fuente Reina" al norte del término municipal, mientras que el resto del proceso se hace dentro de este edificio en el núcleo urbano de Constantina).

El edificio en sí constituye lo que podríamos llamar un "complejo industrial" de unas dimensiones considerables, $2000 \mathrm{~m}^{2}$ distribuidos en tres niveles. El grueso del edificio se compone de dos salas rectangulares, donde están situados los barriles para el almacenamiento y crianza de los vinos; hay una sala dedicada a la fabricación de aguardiente, con la caldera y alambique, donde se producían las marcas de anís "María Guerrero" y "el Zorro Azul"; la recepción donde se invita al cliente a la cata de vino, procedente de la "sacristía" o sala contigua donde se almacenaban los vinos criados en los barriles de mejores madres, (actualmente vendida a una bodega de Palma del Río). El resto del edificio está en unas condiciones de ruina inminente, y todavía alberga intacta la destilería, una gran cantidad de barriles, muchos de ellos con vino, e innumerables botellas de vino y aguardiente.

Este edificio es aún hoy un testigo de la importancia del vino para esta zona. Los mostos, que antaño se exportaban como caldos a criar en otras bodegas, fueron celosamente envejecidos y criados por este "viñaero", en la propia Constantina. Supo elaborar y envejecer vinos de alta calidad, tintos de mesa fabricados a partir de las uvas garnacha, aragonés y carrasquero, así como vinos blancos finos, ligeros, al estilo sanluqueño de las uvas Pedro Ximénez, Jaén, Matuo, etc. La fama que alcanzaron los vinos de Fuente Reina dentro y fuera del municipio, hace que hoy algunos sigan disputándose las madres de sus toneles, en los cuales dejan criar soleras y oloroso al estilo jerezano.

En definitiva, la importancia socioeconómica y cultural de este cultivo, por lo que supone vivir en gran medida y durante tanto tiempo de la viña y los vinos a un grupo social, considerablemente amplio, de forma directa o indirecta, impidió que la viña desapareciera repentinamente después de la crisis de la filoxera, pero a lo largo de estos 60 años, de baja rentabilidad, mantener la viña era casi imposible. Ahora mismo las que quedan están muy envejecidas, no se reponen las cepas, y son básicamente pequeñas explotaciones familiares a las que se le dedica un cuidado intensivo desproporcionado en relación a la baja rentabilidad económica que les reporta.

Si tenemos en cuenta todo este pasado vitivinícola de la Sierra, resulta difícil comprender hasta qué punto ha caído en el olvido este patrimonio cultural, cómo se está borrando de la memoria histórica de sus propios habitantes una actividad antaño tan importante, hasta el punto que actualmente uno puede ser multado si planta vides en estas tierras, ¿cómo es posible que los responsables del parque natural ignoren hasta este punto cuál es el patrimonio cultural de la Sierra Norte, con esta insistente actitud conservacionista y naturista, que pasa por alto una de las improntas más evidentes y menos dañinas de la acción antrópica sobre el medio?, ¿qué parque "natural" queremos crear?

Actualmente, un bodeguero de origen navarro, productor de vino de la Rioja de gran calidad, está recuperando la presencia del viñedo en Constantina a pesar de las reticencias de los responsables del Parque Natural, que consideran que éste no es un cultivo autóctono de la sierra, producto quizás de la ceguera histórica y paisajística que les achaca. $\mathrm{Ha}$ replantado de viña una finca denominada la Purísima Concepción?' y ha comprado también la bodega de Fuente Reina, antes citada, para restaurarla y reactivarla como centro de elaboración de "Vino Tinto Andaluz". Como vemos se está recuperando este riquísimo patrimonio ${ }^{10}$, y existe una intención explícita de ponerlo en valor como algo propio y característico de la Sierra, no sin ignorar que bajo todo ello existe una intención lucrativa, pero que no convierten al producto final en una falsa cultura turística inventada o creada de la nada, sino más bien es consecuencia de una sensibilidad capaz de ver en esta actividad vernácula un "recurso" cultural inigualable para la Sierra Norte de Sevilla.

Otra de las actividades de singular importancia y tradición en la Sierra Norte es la fabricación de anisados. El anís verde o de matalahuva, llegó a Andalucía de mano de los árabes, que importaron la receta griega (mastika y ouzo) junto al sistema de elaboración en alquitaras o alambiques, para su destilación. La época de mayor producción de aguardiente en Andalucía es el siglo XIX y, según Capel (1988), la causa que impulsa este auge en algunas zonas de nuestra región, como Ojén (Málaga), Rute (Córdoba), Cazalla y Constantina (Sevilla) y Zalamea (Huelva), es la combinación de tres factores fundamentales como son la eliminación de monopolios estatales que disminuyen las tasas que gravaban esta actividad; el duro trabajo minero para el que el aguar- 

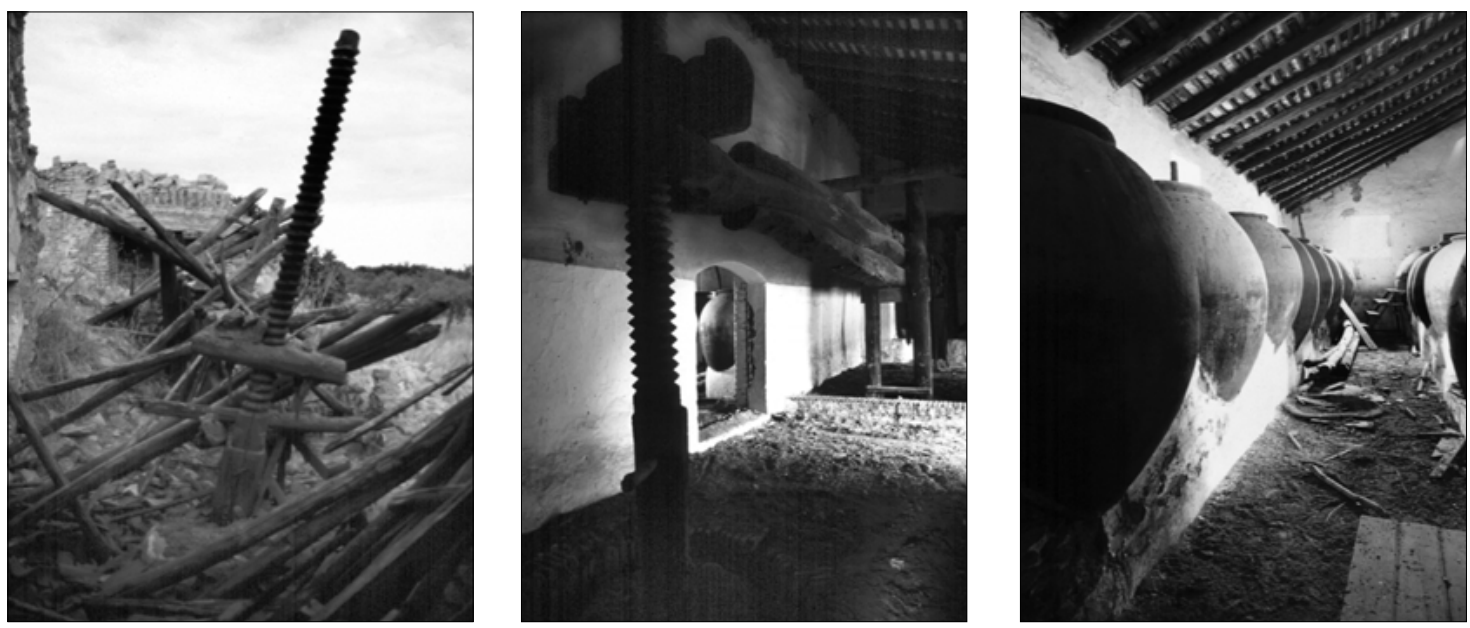

El cultivo de la viña en Constantina (II). Edificios para la transformación de la uva: Lagares.
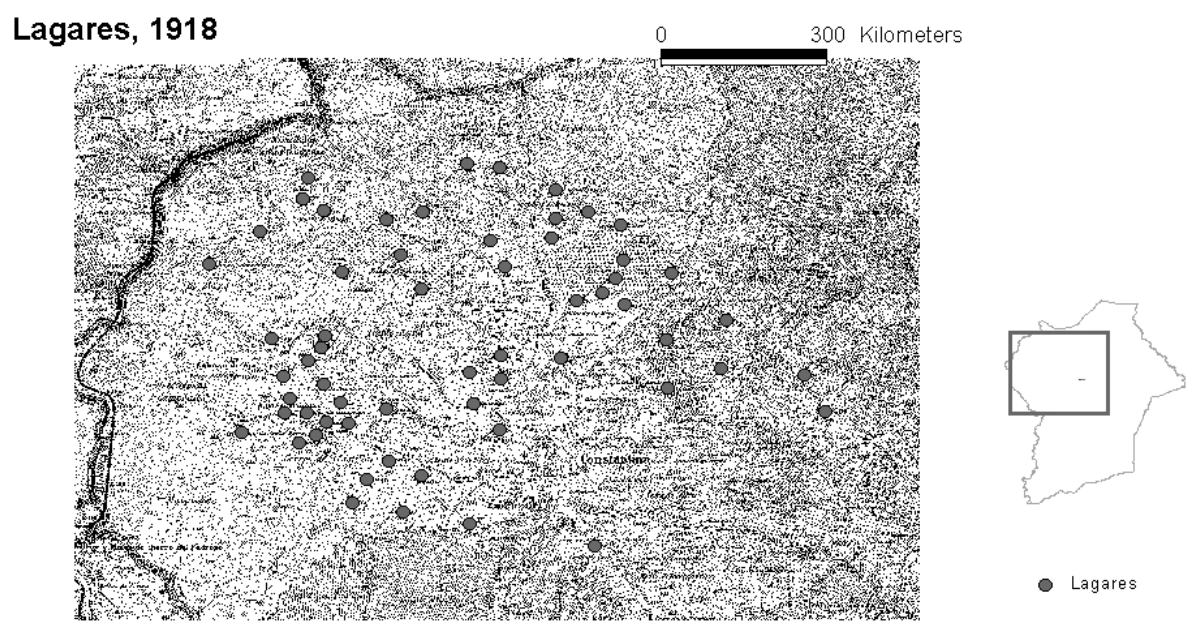

- Lagares

\section{Lagares, 1999 (actualmente en desuso)}

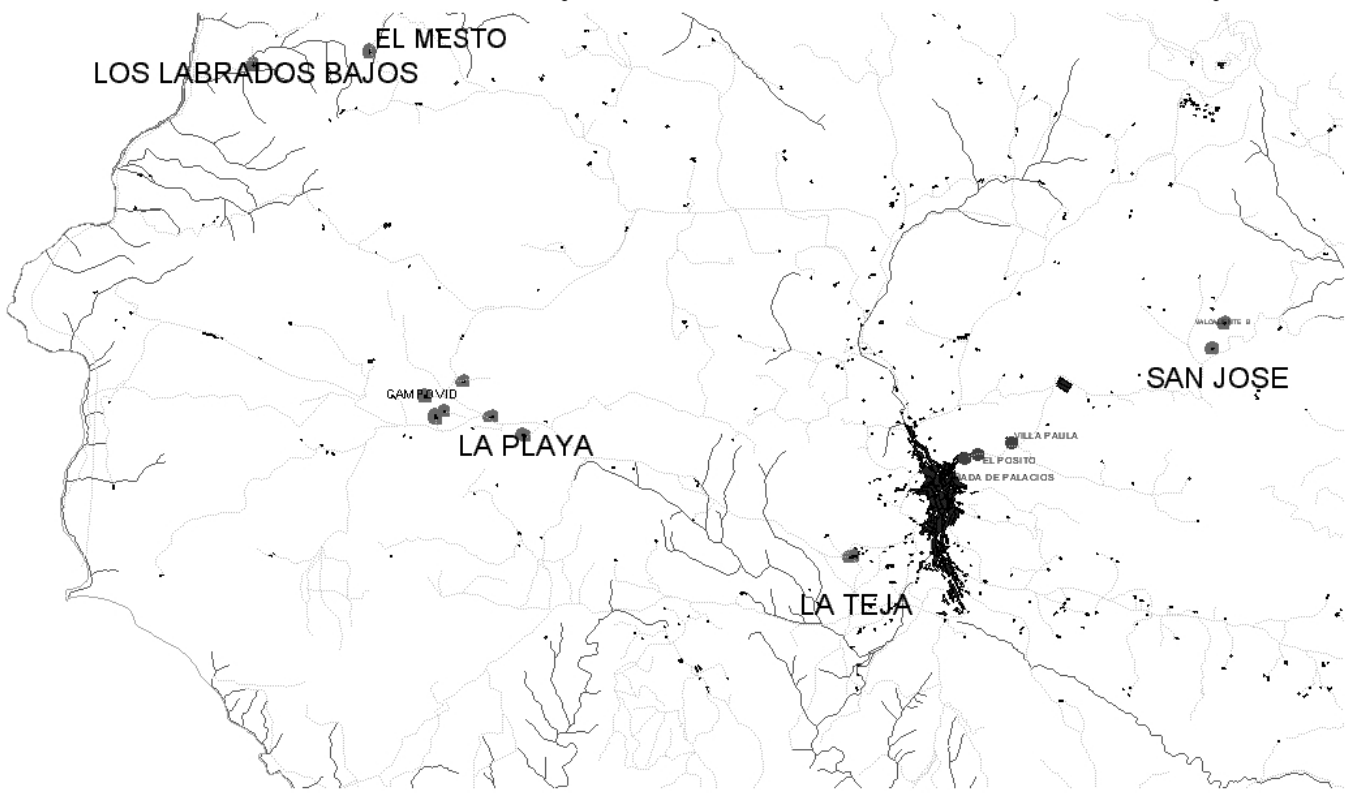




\begin{tabular}{|c|c|c|c|c|}
\hline Tipos & Definición & Tamaño / explotación & Estructura del edificio & Edificios de Constantina \\
\hline Lagaretas & $\begin{array}{l}\text { Espacio destinado } \\
\text { a la pisa de uva }\end{array}$ & Pequeñas de escasa producción & $\begin{array}{l}\text { Habitación rectangular, piso inclinado } \\
\text { que conduce el caldo a los muretes. } \\
\text { Tiene pocas tinajas. Se da en propiedades } \\
\text { pequeñas o donde la producción de vid } \\
\text { es secundaria. }\end{array}$ & \\
\hline $\begin{array}{l}\text { Lagar de prensa } \\
\text { de viga }\end{array}$ & \multicolumn{2}{|c|}{$\begin{array}{l}\text { Edificios de una mayor } \\
\text { complejidad. Destaca el } \\
\text { artilugio mecánico que } \\
\text { alberga y lo determina en su } \\
\text { forma. Está compuesto por: } \\
\text { - Lagareta } \\
\text { - Torre de prensa } \\
\text { - Castillete } \\
\text { - Bodegas } \\
\text { - Vivienda }\end{array}$} & $\begin{array}{l}\text { La prensa de viga marca la estructura } \\
\text { longitudinal del edificio. La necesidad } \\
\text { de movimiento de la viga para presionar } \\
\text { la uva, con un mecanismo de contrapesos, } \\
\text { justifica la forma de la torre de prensa } \\
\text { En la crujía paralela a la prensa suele } \\
\text { encontrarse la bodega, con un número } \\
\text { de tinajas que oscila entre } 15-30 \text {. } \\
\text { Suelen ser de dos metros de altura por } \\
1.50 \text { m de diámetro en la parte más ancha. }\end{array}$ & $\begin{array}{l}\text { - La Purísima Concepción } \\
\text { - Los Labrado Bajos } \\
\text { - El Mesto } \\
\text { - Campovid } \\
\text { - La Playa } \\
\text { - El Guerrilla } \\
\text { - Valcaliente } \\
\text { - San José }\end{array}$ \\
\hline $\begin{array}{l}\text { Lagar de prensa } \\
\text { de husillo o jaula }\end{array}$ & & & $\begin{array}{l}\text { Espacio cuadrado o rectangular donde } \\
\text { se unen los espacios anteriores } \\
\text { (nave de prensa y lagareta). Contiene la } \\
\text { moledora mecánica (a mano o motor), } \\
\text { la prensa de jaula y la pequeña lagareta }\end{array}$ & $\begin{array}{l}\text { - El Pósito } \\
\text { - Cañada de la Jara } \\
\text { - Villa Paula. }\end{array}$ \\
\hline
\end{tabular}

BODEGA DE FUENTE REINA, FUNDADA EN 1930

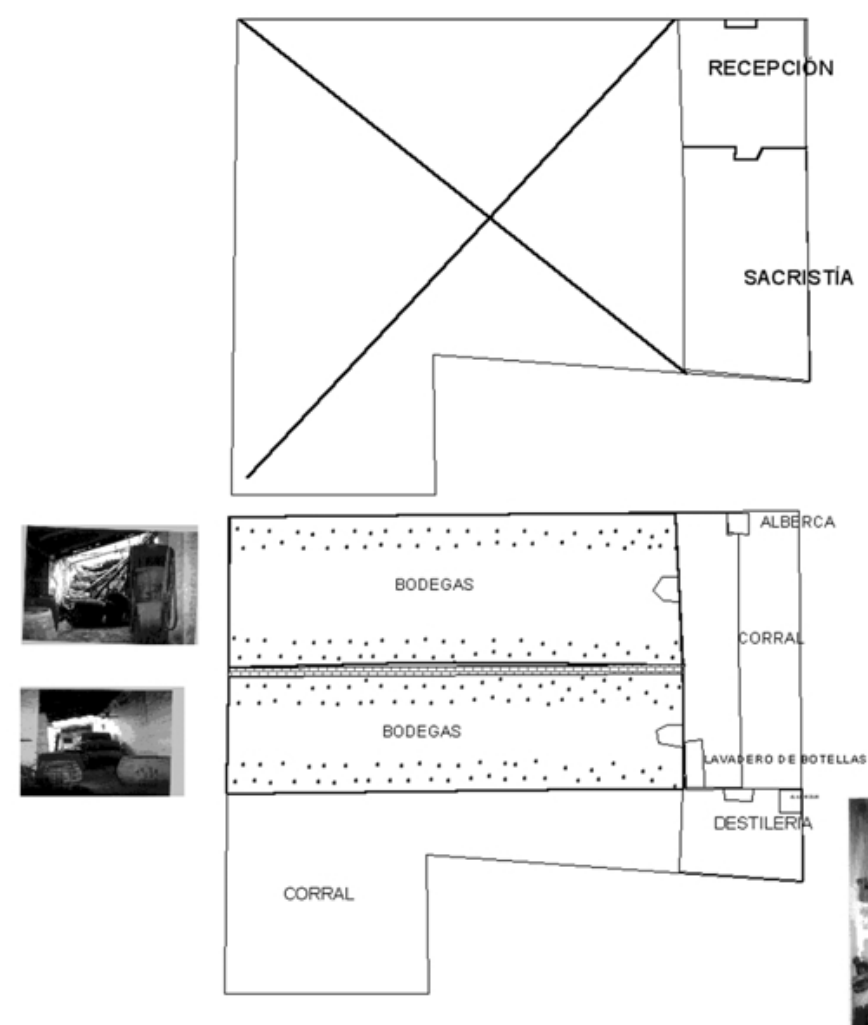

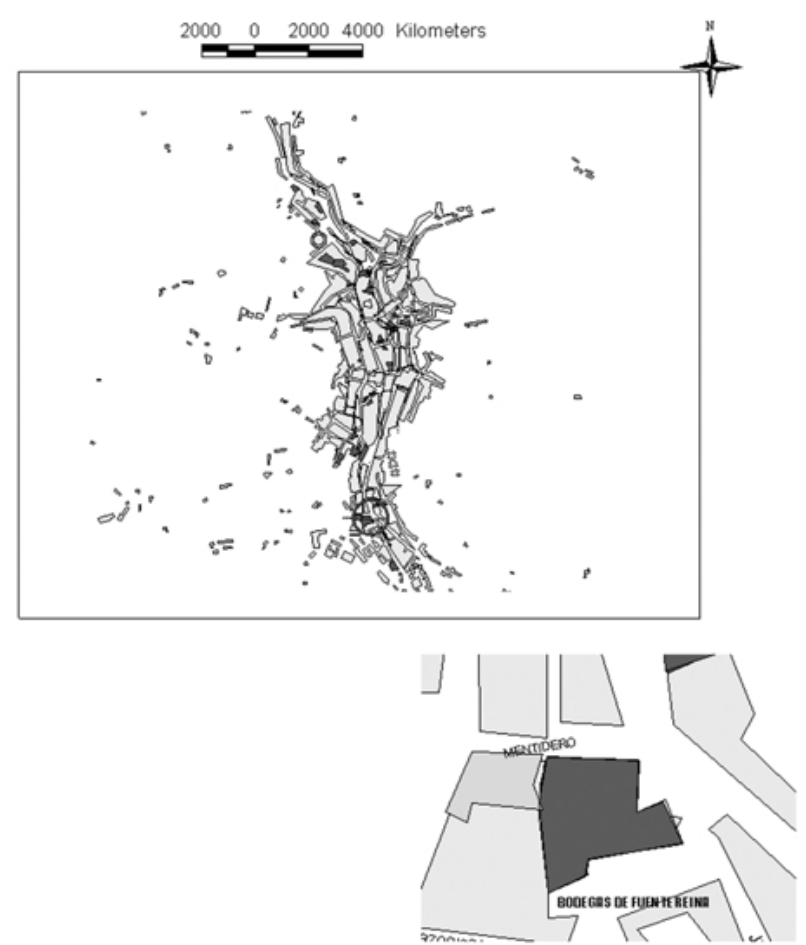




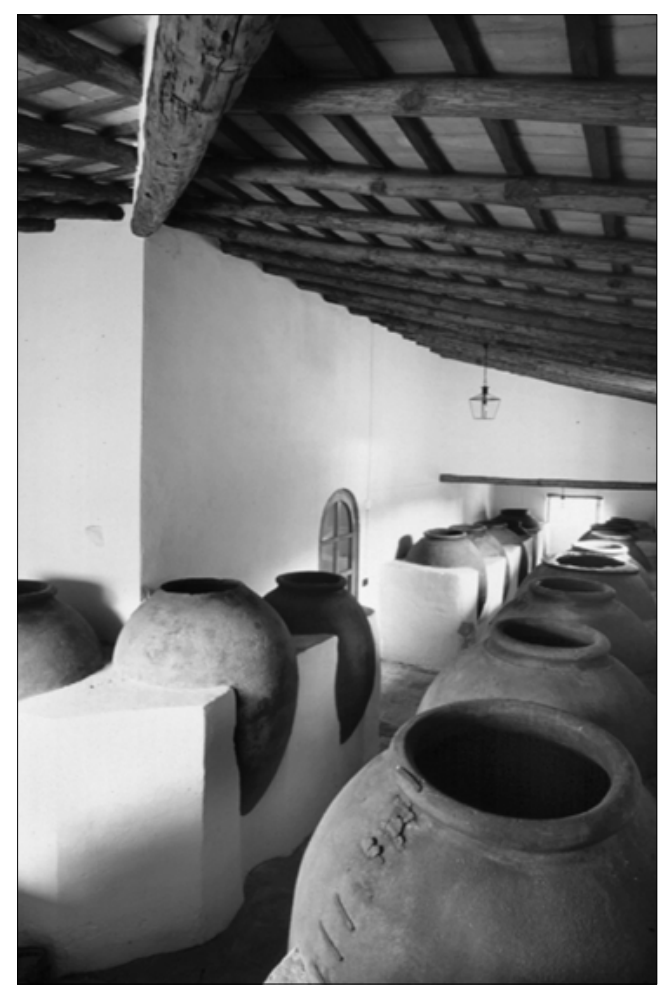

diente adquiere cualidades terapéuticas contra las enfermedades de las vías respiratorias II; y por último, por la presencia junto a estos centros mineros de abundantes recursos naturales como agua y madera por la combustión (muy arraigado en el imaginario colectivo).

Su origen en la Sierra Norte se remonta al siglo $X V I I I$, cuando la mayor parte de las fincas de la sierra sevillana, y sobre todo las de Cazalla y Constantina, instalaron junto a sus lagares, las calderas y alquitaras.

En el caso concreto de Constantina, sin descartar estos factores, creo que es interesante entender el protagonismo de la burguesía agraria local para explicar el auge de esta actividad: en especial, su capacidad para adaptarse a los cambios mediante diferente estrategias comerciales. Con la producción de aguardiente, la Sierra Norte entra plenamente en la economía de mercado, desarrollando durante el primer tercio del siglo $X X$ estrategias avanzadas de publicidad, propaganda y redes de comercialización a pequeña y mediana escala, así como un entresijo productivo que se conformó en torno a esta actividad que generó todo un circuito de empresas satélites, ya sean de origen local: fábrica de tapones, fábrica de fundas de esparto para garrafas, empresas de transportes, de "viajantes" o comerciales que se recorrían todo el territorio del estado; así como empresas de otras zonas: industrias de litografías para el etiquetaje de origen alemán y asentada en Jerez de la Frontera; fabricantes de alambiques (unos maestros italianos de la c/ Feria de Sevilla).

En principio el aguardiente nació en la sierra como un producto derivado de la vid, de forma que los exce- dentes de uva se utilizaban para fabricar alcohol vínico ${ }^{12}$ que serviría como base para la destilación. Pero si importante fue el cultivo de la vid en esta zona, su decadencia y desaparición, no implicó en ningún momento la desaparición de la fabricación de anisados, sino que ésta trascendió en importancia y en tiempo a la explotación del viñedo y a la producción de vinos. El aguardiente y las fábricas de anisados alcanzan su auge en Constantina durante el siglo XIX y primer tercio del $X X$, y sus escasos resquicios perduran hasta hoy. Durante este período se convirtieron en parte fundamental de la industria de la zona, en una de las bases económicas de muchas familias de Constantina, en elemento fundamental de los hábitos de consumo relacionados con el trabajo y con las fiestas y reuniones, en un referente clave de identificación local, que conformó la base para definir una y varias culturas del trabajo (la de los cocederos, la de los "viajantes", etc.).

A partir del aguardiente, la producción de bebidas alcohólicas se diversifica. La propaganda insiste para que su consumo se adapte a las diferentes ocasiones diarias y festivas y también a los distintos sectores sociales. La necesidad de permanecer y reproducirse, fue originando un continuo de estrategias comerciales y productivas para salvar las dificultades que suponían la inserción de esta industria dentro de un mercado cada vez mayor. A ello responde la búsqueda de sabores nuevos y de licores (ver etiquetas) que multiplicarían la oferta para surtir una demanda, que empezaba a ser cada vez más exigente por la llegada de nuevas bebidas al mercado.

Desde mi punto de vista la desaparición de una industria que había generado más de 40 empresas dedicadas a la producción de bebidas en Constantina, junto a las empresas indirectamente vinculadas a esta actividad, se debe, no a la falta de una clase social "emprendedora" y con falta de dinamismo, sino al hecho de que no existió o fue poco representativo, un sector social intermedio que hiciera de esta actividad industrial autóctona la fuente prioritaria o única de sus rentas, sino que la oligarquía agraria controló y personalizó todo el tejido económico básico, incluidas las actividades industriales que hubieran podido poner las bases de un desarrollo autónomo y sostenido. Por otro lado, a esto hay que sumarle la poca ayuda prestada por el Estado franquista para tareas que no tuvieran que ver con la agricultura en Andalucía. Éste fue seguramante el mayor detonante y causa del desinterés, por mantener estas fábricas abiertas.

Es decir, la diversificación de las bases económicas, la posesión de tierras y materias primas, las inversiones en distintos sectores, según iba conviniendo por la situación del mercado, los bajos costes salariales, y la concentración de un poder político eficaz, fueron durante mucho tiempo ventajas para la proliferación de industrias en Constantina.

Otra actividad productiva importante en la sierra a nivel económico y cultural que ha dejado sus huellas en el paisaje a través de la arquitectura y de diversas 
Evolución en el tiempo de fábricas y fabricantes de aguardiente en Constantina

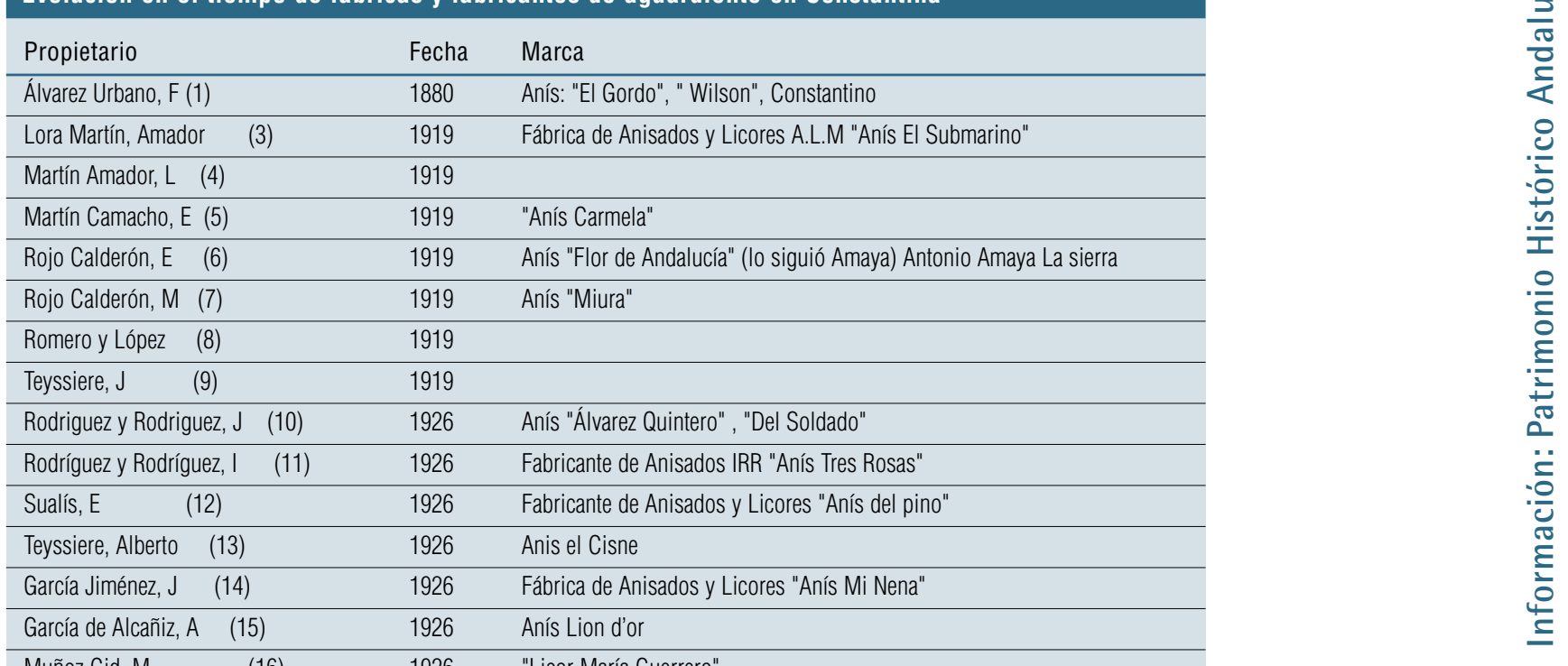

Muñoz Cid, M (16) 1926

Merchán Aranda, Antonio (17)

(18) 1926

González Villardell, Constantina (19) 192

Muñoz Alonso, Enrique (20) 1926

Prieto Vargas, José (21) 1927

Sualís, Enrique (22) 1927

$927 \quad$ Anís Pierrot

Sualis, Enrique (22)

927 Anís "Previsor"

García de Alcañiz (25) 1927

(26) 1928

(27)

1928

Enrique Muñoz (28) 1928

Lemos Ortega, Emilio (29) 1928

Prieto Vargas, J (30) 1929

Gallego de los Reyes, L (31) 1929

Gómez de la Madrid, E (32) 1929

Lora Martín, A (33) 1929

Martín, D.E (sucesor) (34) 1929

Rodríguez, J (35) 1929

Valdecantos, M (37) 1929

Rojo, G. (39) 1935

Martínez Calderón, E (40) 1939

Rojo, R (Hra) 1939

\begin{tabular}{|c|c|c|}
\hline \multirow[t]{2}{*}{ López Redondo, Manuel (41) } & 1945 & Anis Zorro Azul, Cognac Fuente Reina, Ponche "novo" \\
\hline & 1945 & Anís Emperatriz \\
\hline María Cabrera (42) & 1945 & Bodegas Rey Chico: vinos, vinagres, anisados, cognac, vermut \\
\hline \multicolumn{2}{|c|}{$\begin{array}{l}\text { Manuel Amaya (Sucesor de Fco. Rojo) (43) } \\
\text { Flor de Andalucía }\end{array}$} & 1945 \\
\hline & 1945 & Anis Luz \\
\hline Pablo Rivas (44) & 1945 & Anis Kamhel \\
\hline \multirow[t]{4}{*}{ Antonio Lozano (45) } & 1950 & Anis Flor de Sevilla \\
\hline & 1951 & Anís del Mosquito \\
\hline & 1951 & Carmen Alvarez \\
\hline & 1953 & Anís Bulería \\
\hline Hijo de Manuel Rojo & 1953 & Anis Luisa Ortega \\
\hline García González, José (46) & 1961 & Anis la Violetera \\
\hline
\end{tabular}


explotaciones aún en funcionamiento es el cultivo del olivar y la producción de aceite.

Se trata del cultivo arbóreo por excelencia en la Sierra Norte, representa el $99 \%$ de las plantaciones leñosas, aunque hoy día, se haya en regresión, ocupando sólo 16.000 ha dentro del parque natural; sobre todo en Constantina, Cazalla y Guadalcanal, (con unas 2500 ha cada uno), seguidos por Alanís, las Navas y El Pedroso.

Comenzó a tener importancia en la Sierra a partir de la crisis de la viña, acompañada del aumento del olivar, primero en cultivos mixtos con viña y frutales, y posteriormente ocupando todo el espacio que habían dejado las viñas arrancadas, (mapa de cultivos de 1990).

El olivar ha tenido importantes repercusiones a nivel económico, social y cultural en Constantina, y de ello son testigo las almazaras y molinos aún existentes en su término. La acumulación de instalaciones creadas con este fin, nos sugieren que Constantina actuaba además como centro de producción de aceite de toda la comarca, es decir, se molían frutos que llegaban de otras poblaciones menores, por medio del transporte de arriería o carretería.

Y de todo ello nos quedan testimonios agrícolas, arquitectónicos, tecnológicos y todo un colectivo social que ha trabajado y continúa trabajando en actividades relacionadas con el cultivo del olivar y la producción de aceite, por lo que nos atrevemos a afirmar que el territorio de Constantina está fuertemente marcado y definido por este cultivo. Tecnológicamente, las transformaciones han sido importantes, y concentradas en un período de tiempo breve: los antiguos lagares de prensa de viga fueron convertidos en almazaras, y estas a su vez fueron sustituidas por las prensas de Husillo o jaula y más tarde, muchas de ellas fueron desplazadas, en los años 20-30 de este siglo, por las llamadas "fábricas de aceite", que contenían una prensa hidráulica que funcionaba con una máquina de vapor, dejando obsoleta a las

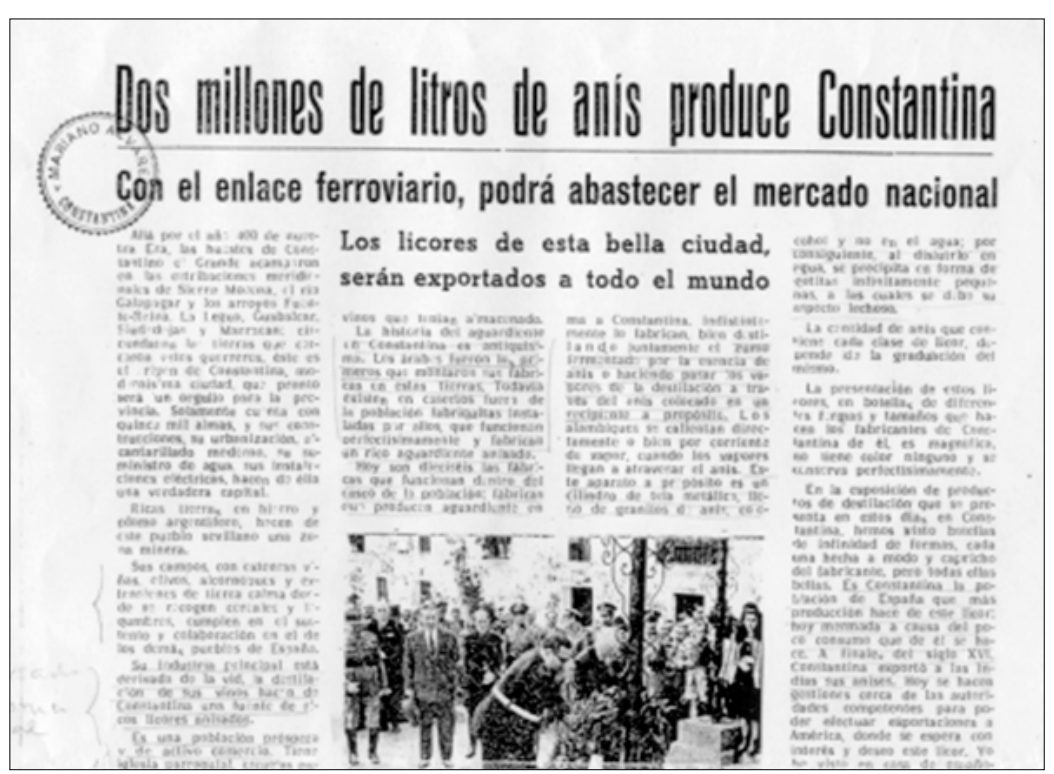

viejas prensas de viga. De todos estos artilugios que se han ido sucediendo para desembocar en la actual almazara cooperativa, quizás el más significativo, en Constantina, sea la almazara de prensa de viga, heredera directa del lagar. Tecnológicamente está basada en un principio técnico sencillo y eficaz: el del funcionamiento de una palanca, en el que la que la resistencia (materia a prensar) está situada entre la potencia (contrapeso con tuerca) y el punto de apoyo.

Más tarde, una nueva revolución: los molinos industriales; estos fueron montados por los grandes propietarios olivareros en sus fincas (en la hacienda el "El Jardín" se instala una prensa hidráulica comprada en la Exposición Universal de Sevilla de 1929) o bien en el pueblo. Las ventajas de esta nueva prensa eran el ahorro de espacio porque podían instalarse en una nave de 3,5 55 metros; se obtiene el aceite de una sola presión, se ahorra en capachos por su menor diámetro, y disminuye considerablemente el consumo de fuerza, funciona con sólo dos operarios, no se emplea el aguado y suprime el moledero de piedra. Pero el cambio implicaba una inversión que como las anteriores, sólo pueden permitirse los grandes propietarios. Más tarde los precios abusivos que imponían los propietarios llevará a crear la almazara cooperativa. El olivar es la única y primera entre todas las actividades económicas que se desarrollaron en el término que consigue unirse en cooperativa, lo cual ha garantizado por el momento su continuidad ${ }^{13}$, leve pero constante.

Si hasta el siglo XIX la sierra contaba con explotaciones caracterizadas por una conjunción de cultivos, la crisis progresivas de cultivos como la vid primero y el olivar después, ha marcado la tendencia hacia un adehesamiento progresivo del territorio serrano.

La dehesa constituye un sistema de explotación complejísimo de aprovechamiento del medio basado en la complementariedad de diferentes actividades económicas agrícolas, forestales y ganaderas, que le otorgan dinamismo y flexibilidad ante los cambios gracias a la diversidad de combinaciones que permite en el aprovechamiento de los recursos. Su rentabilidad depende del equilibrio entre el aprovechamiento de los pastos, cultivo del suelo y cuidado del arbolado (encinas y alcornoques), para la obtención del fruto que sirve de alimento al ganado (la bellota), así como del manejo adecuado del ganado. Como la dehesa ya ha sido suficientemente estudiada y analizada (Hernández León, 1998:57), me gustaría poner el punto de mira sobre las actividades industriales que ha generado, como por ejemplo la producción de corcho, principal aprovechamiento forestal de la dehesa.

Las cualidades esenciales que hacen al corcho un producto tan apreciado en le mercado y codiciado por las principales industrias del mundo son su escasa densidad, gran elasticidad y flexibilidad, por lo que resulta excelente como aislante del sonido, de la temperatura y de la electricidad. Potencialidades que se han aprovechado escasamente en una de sus principales zonas de producción: la Sierra Norte de Sevilla. 


\section{Extensión del olivar}

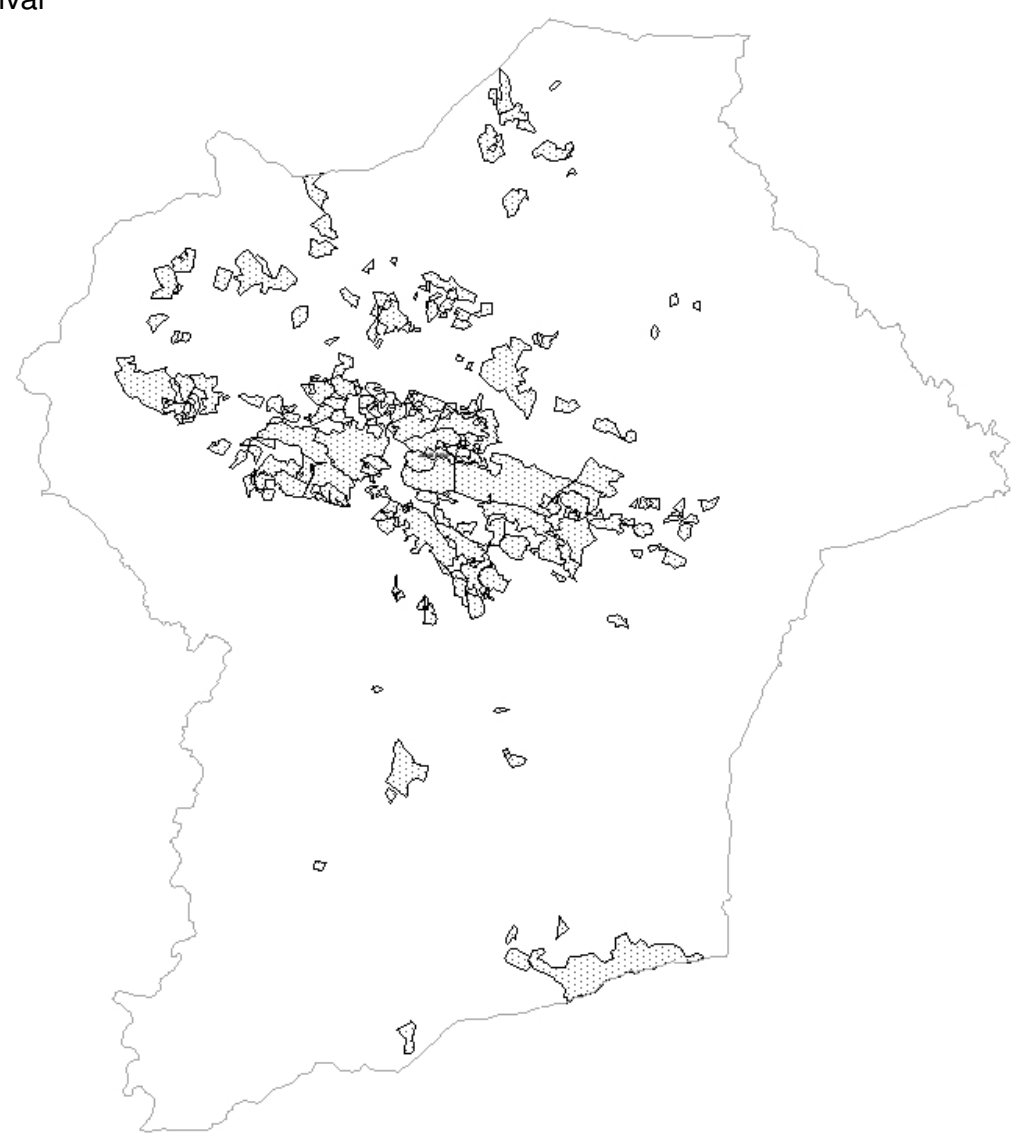

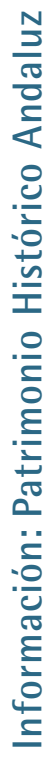

Almazaras, 1918

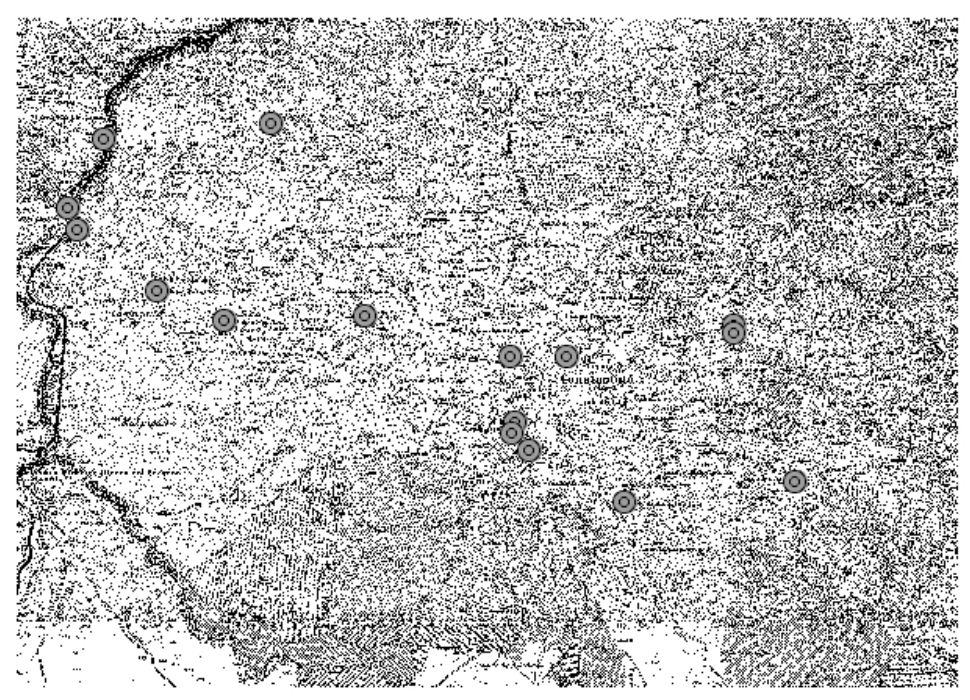

600
600 Kilometers
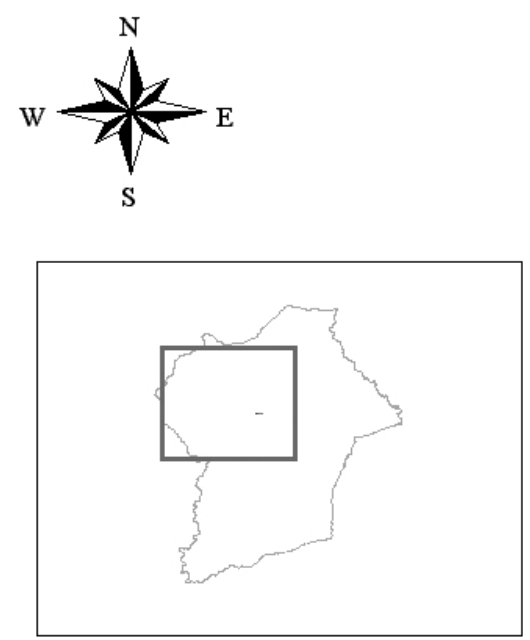

(2) Molinos 

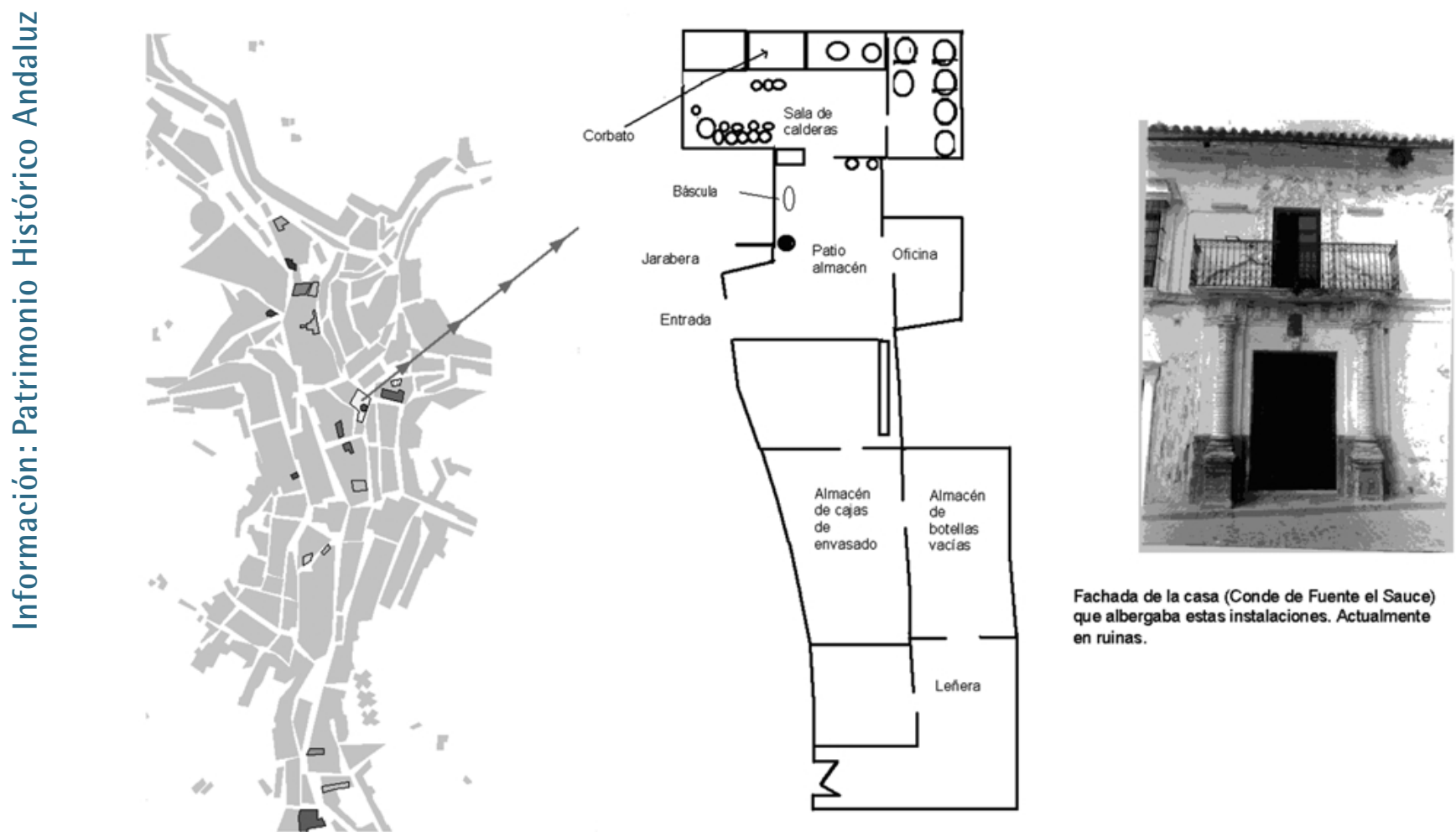

Fachada de la casa (Conde de Fuente el Sauce) que albergaba estas instalaciones. Actualmente en ruinas.

Plano de la Fábrica de Anis La Violetera, 1960.

Desde 1926 a 1930, el mercado del corcho en el Estado español conoce su época de mayor esplendor ( | | 2.000 t), sin embargo el período de la guerra civil y el régimen franquista supusieron un receso enorme ya que a partir del embargo económico a España, ésta dejó de ser la primera productora de corcho, pasando a ocupar el primer puesto Portugal que se preocupó de replantar alcornoques, en tanto que en España se esquilmaba buena parte de la cubierta vegetal para la plantación de eucaliptos dirigidos a la industria papelera.

Durante los años 20-30 existieron dos protoindustrias corcheras ${ }^{14}$ en Constantina: la fábrica de Zacarías Prado, que fabricaba aglomerados negros de bornizo, que servían como aislante: "Ese corcho cocido iba a Cataluña y a Inglaterra. Es donde estaban las fábricas de moler que compraban el refugo para el aglomerao, los aislamientos. Aquí se hacía lo más rústico"; y más tarde se convirtió también en fábrica de tapones para abastecer a la industria local de anisados y vinos, "y luego ya mi abuelo se dedicó a hacer tapones, que lo llamaban un bolichero, los principiantes" (nieta de fabricante de corcho); otra de las fábricas de corcho de Constantina pertenecía a Francisco Álvarez, (a su vez, fabricante de anisados, y de embutidos) con una pequeña producción para autoabastecimiento y el resto para la exportación.

También las fábricas de embutidos o de curtido, que suponían la transformación de productos derivados del ganado, han desaparecido en Constantina. Ahora se vende la mayor parte del ganado porcino, criados en las dehesas locales, a las fábricas de embutidos de Salamanca.
Es decir, la Sierra Norte, y concretamente Constantina, ha cerrado sus industrias, ha modificado su paisaje, sus edificios, su tecnología, sus sistemas de aprovechamiento tradicionales, sus actividades artesanales e industriales con siglos de historia de saberes aprendidos y enseñados de generación en generación. Todo ello es fruto del proceso de desarticulación sectorial que ha experimentado esta zona durante la segunda mitad del siglo XX, que ha quedado relegada a la producción de materias primas y al desarrollo de las actividades con menor valor añadido del sistema productivo, primero en el contexto del Estado, y actualmente a tenor de las políticas agrarias comunitarias.

Todas estas actividades productivas y el cúmulo de experiencias y prácticas que se han desarrollado en el seno de estos territorios hoy considerados "parques naturales", pueden servirnos para cuestionar esa imagen de entorno inalterado, producto del desconocimiento de la historia más reciente de la Sierra Norte, olvidando o ignorando parte de lo que han sido los sistemas de aprovechamiento tradicionales que han coexistido durante este siglo, que han contribuido a crear unos paisajes culturales que deben ser valorados como una parte más de las señas de identidad de la cultura andaluza, en un doble sentido: por un lado atestiguan el pasado en el que se ha venido produciendo y cambiando esa relación sistémica entre cultura y medio; y, en segundo lugar y no menos importante, constituyen una creación del presente, abierta a nuevos usos y transformaciones, como es propio de toda dinámica cultural. (J. Agudo, 2000). 


\section{Bibliografía}

\section{AGUDO TORRICO, J. Y GIL GONZÁLEZ, C.}

1982. Los caseríos de viña y olivar en Cazalla de la Sierra (SeviIla): Pervivencia y transformación en relación con la economía agraria. Tesis de Licenciatura (sin publicar). Universidad de Sevilla.

1984. "Caseríos de lagar en el término de Cazalla de la Sierra (Sevilla): Transformación y pervivencia en relación con los cambios producidos en la base de economía agraria". En S. Rodríguez Becerra (Coord.), Antropología Cultural de Andalucía. Junta de Andalucía. Sevilla. Págs. 547-560.

1993. "Aprovechamientos endógenos de los recursos naturales y preservación del patrimonio etnográfico de la Sierra Norte de Sevilla". I. González Turmo. (Coord.) Parques Naturales andaluces. Conservación y cultura. Junta de Andalucía. Sevilla.

1999. "Espacios naturales, territorio y patrimonio cultural". En Naturaleza de Andalucía. Vol. V: El Medio Ambiente Urbano e Industrial. Ed. Giralda. Sevilla (1997). Pp. I6-57.

1999. "Cultura, patrimonio etnológico e identidad". Boletín del Instituto Andaluz del Patrimonio Histórico. №. 29. Sevilla. págs. 36-45.

BERNABÉ SALGUEIRO, A. 1998. La arquitectura vernácula diseminada en Constantina (Sevilla) Economía, prestigio social y representaciones ideológicas. Producciones Culturales del Sur. Sevilla.

GARRABOU, R. Y SANZ, J. 1985 Historia agraria de la España Contemporánea. Crítica. Barcelona.
GODELIER, M

1984. Lo ideal y lo material. Taurus Humanidades. Madrid. Gordon Peral, Ma D.

1988. Toponimia de la Sierra Norte de Sevilla. Servicio de Publicaciones de la Universidad de Sevilla. Sevilla.

HERNÁNDEZ LEÓN, H. 1988 Una arquitectura para la dehesa: el Real de la Jara. Estudio antropológico de las edificaciones diseminadas por la Sierra Norte. Diputación de Sevilla. Sevilla.

LEY |/|99|, de 3 de julio, de Patrimonio Histórico de Andalucía. Junta de Andalucía. Delegación Provincial de Cultura y Medioambiente. Huelva.

LEY 4/1999, de 15 de marzo. (BOE 85/99, de 9 abr.) de Patrimonio Histórico de Canarias.

MADOZ, P. 1984 (I850) Diccionario Geográfico Estadístico-Histórico de España y sus posesiones de Ultramar. Madrid.

MORENO NAVARRO, I. 1981. "El cultivo de la viña, la fabricación de aguardiente y la colonia agrícola de Galeón: estudio etnológico de la evolución y crisis de las actividades económicas tradicionales de Cazalla de la Sierra (Sevilla). Etnografía española 2: 187-254. Madrid.

NADAL, J. 1983 "Los dos abortos de la revolución industrial en Andalucía", en Historia de Andalucía. Edit. Planeta S.S. Madrid. Vol. Vl, pp. 399-433.

\section{Notas}

I. Con las desamortizaciones tanto eclesiástica (Mendizábal1836) como civil (Madoz- 1855), que aseguran el triunfo de los principios burgueses dentro del sistema agrario, las tierras señoriales, comunales y las pertenecientes a la iglesia se transforman en propiedad privada sin ningún tipo de vinculación inamovible. Estas desamortizaciones suponen el mayor trasvase de propiedad agrícola en la historia de Andalucía con drásticas consecuencias en la estructuración socioeconómica y política andaluza, tales como el declive de la importancia de los concejos como entes locales dotados de cierta autonomía en cuanto a la gestión de importantes recursos colectivos, y la fuerte bipolarización social que ocasionó supondrá la nueva distribución y control de la tierra como medio de producción básico.

2. A partir del segundo tercio del siglo XIX y en relación con la concentración de propiedad resultante de las desamortizaciones se asiste a un desarrollo continuo del capitalismo en el sector agrario (Garrabau y Sanz, 1985; I. Moreno, 1977: 9): inserción de la producción agrícola en los mercados internacionales, crecimiento de la producción, consolidación de la propiedad burguesa frente a las pequeñas propiedades campesinas...lo cual pondría en tela de juicio la idea generalizada de que estas grandes pro- piedades mantuvieron un patrón económico arcaico e inmovilista, o que no existían unas clases capaces de impulsar al desarrollo capitalista.

3. Se pueden citar algunos como el "Fuente y Regajo de la Peñuela; Fuente y corriente del Robledohermoso hasta el castaño Gordo; Fuente y Regajo de la Sierva hasta la Hacienda de Da Ángeles López; Fuente y Regajo de la Alamedilla-Monteros; Fuente del Hornillo en el sitio de las Hermanillas desde el nombrado Rodeillo de Ma Aparicio hasta el arroyo de Masacón;...".

4. "aquellos parajes naturales, construcciones e instalaciones vinculados a formas de vida, cultura y actividades tradicionales del pueblo andaluz, que merezcan ser preservados por su interés etnológico".

5. La arquitectura y el hábitat en general, constituye un testimonio etnográfico, que unido a otra de las principales fuentes de información con la que cuenta la antropología, la información oral, constituye un texto documental de primer orden, porque los edificios son testigos y testimonio de la relación histórica del hombre con el medio físico, y por lo tanto una fuente elemental 
para poder analizar los sistemas de aprovechamiento que han imperado en estas poblaciones, procesos de transformación utilizados, modos de vida, y las relaciones sociales que se desarrollaron, así como las distintas facetas en que se han ido poniendo en práctica los diversos sistemas tecnoeconómicos, organización social, representaciones colectivas etc.

6. La situación geográfica de la Sierra Norte, hoy quizás marginal, favoreció en el siglo XVI las relaciones comerciales con América. Entonces compensaba saltar la distancia, relativamente pequeña entre la Sierra Norte y el puerto de Sevilla desde donde salían todos los fletes a las Indias.

7. "se ejercitan varios objetos de industria, siendo el principal de ellos la fabricación de aguardientes y preparación de vinos, cuyos líquidos, el aceite y las maderas de castaño que tanto abundan... Continuamente se emplean un gran número de carretas en la exportación a Extremadura y Andalucía de dichos artículos, con lo que y el cultivo de su campo se sostiene la riqueza de su pueblo. Hay 14 molinos harineros, 9 de aceites y 780 lagares, una fabrica de curtidos, una de jabón y varias de aguardiente". (Pascual Madoz, 1984 (1850).

8. En las fotos pueden apreciarse dos lagares de prensa de viga: "La playa" y "Campovid". El primero está en ruinas desde hace aproximadamente 5 años, y al segundo le espera la misma suerte, si no se interviene urgentemente. En la tercera fotografía aparece la bodega de lagar de Campovid.

9. Ha restaurado el lagar de prensa de viga (sin la viga), que conserva aún la bodega de 30 tinajas (siglo XVII), y la nave de prensa de viga, que por las dimensiones de la nave debía de ser de un tamaño insólito en la zona, propio de un gran centro de producción vitivinícola.
10. En la fotografía podemos apreciar la bodega restaurada.

II. En este sentido, Pascual Madoz, en su descripción de la mina del Pedroso resalta el hecho de que la "fábrica consume en 24 horas 800 arrobas de vino y posee varias calderas o alambiques para aguardiente anisado de muy buena calidad" (Madoz, 1984(1850).

12. Son abundantes las referencias a este origen del aguardiente: "las viñas, los excelentes y copiosos vinos que como cosa particular son buscados de muchas y dilatadas provincias, y abastecen a los pueblos de las cercanías, siendo tanta su cosecha que ascenderá de setenta a ochenta mil arrobas. También se sacan de ellos aguardientes muy buenos que se gastan en las Andalucías y Extrermaduras para cuyos efecto se cuentan existen más de veinte fábricas" (I780).

"Los viñedos dieron origen a la industria de anisados", que animaba como lo hace la industria, la vida del pueblo y llevaba su nombre sobre las botellas de sus exquisitas marcas a todos los mercados del mundo. (López Redondo, M: 1952).

13. La Cooperativa Agropecuaria y Caja Rural "Virgen del Robledo" fundada en 1960 en la Hermandad de Labradores, asocia a todos los olivareros del término, tiene seis prensas con centrifugadoras que proporcionan caldos de buena calidad; cuenta actualmente con 500 socios de derecho.

14. Actualmente las únicas fábricas de corcho que quedan en la Sierra Norte son tres, ninguna de ellas en Constantina: Corchos de Cazalla S.L (Cazalla); Cortansa y Diego Rodríguez y Sucesores (El Pedroso) 